\title{
Dissolved organic matter and estrogenic potential of landfill leachate
}

\author{
Fan Lü ${ }^{a, b, c}$, Hua Zhang ${ }^{a, b}$, Cheng-Hsuan Chang ${ }^{b}$, Duu-Jong Lee ${ }^{b, *}$, Pin-Jing He ${ }^{a}$, Li-Ming Shao ${ }^{a}$, Ay Su $^{c}$ \\ a State Key Laboratory of Pollution Control and Resource Reuse, Tongji University, Shanghai 200092, China \\ ${ }^{\mathrm{b}}$ Department of Chemical Engineering, National Taiwan University, Taipei 10617, Taiwan \\ ${ }^{\mathrm{c}}$ Department of Mechanical Engineering, Fuel-Cell Center, Yuan Ze University, Taoyuan 320, Taiwan
}

\section{A R T I C L E I N F O}

\section{Article history:}

Received 24 November 2007

Received in revised form 29 March 2008

Accepted 6 April 2008

Available online 23 May 2008

\section{Keywords:}

Dissolved organic matter

Leachate

Size exclusion chromatography (SEC)

Estrogenic potential

\begin{abstract}
A B S T R A C T
The estrogenic potentials of leachate samples collected at Laogang Sanitary Landfill in Shanghai, China were measured together with the associated dissolved organic matter (DOM) in leachate samples. Over 99\% of the DOM in fresh leachate was removed upon 3-7 years of landfill, leaving only DOM with strong fluorescent activity. Anoxic or aerobic treatment of landfill leachate can further degrade DOM of $\mathrm{MW}<300 \mathrm{Da}$ and transform those with fluorescent activity of MW $>10^{5}$ Da to those of $2000-10^{5} \mathrm{Da}$. Neither landfilling nor storage in anoxic pond effectively removed estrogenic potential of leachate. Fractionation test revealed that residual organic matters of MW 3000-14000 Da and of $<600$ Da with high $\mathrm{UV}_{254}$ contributed most of the estrogenic activities in leachate. Aerobic SBR treatment considerably reduced the estrogenic potential of these organic matters in leachate.
\end{abstract}

(c) 2008 Elsevier Ltd. All rights reserved.

\section{Introduction}

Landfill leachate often indicates potential environmental pollution of groundwater or surface water (Kjeldsen et al., 2002). Dissolved organic matter (DOM) in leachate are composed of organic acid and refractory humic or fulvic-like substances. Filters, resins or field-flow fractionation characterizes the size-distribution of DOM in leachate (Weis et al., 1989; Frimmel and Weis, 1991; Gobbels and Puttmann, 1997; Christensen et al., 1998; Klein and Niessner, 1998; He et al., 2006; Persson et al., 2006; Saadi et al., 2006). Fluorescence excitation and emission matrix (EEM) is applied to provide qualitative characteristics of the chemical nature of DOM in landfill leachate (Baker, 2005; Baker and Curry, 2006).

Endocrine disruptors such as poly aromatic hydrocarbons (PAHs), phthalates (PAEs), and polychlorinated biphenyls (PCBs) were detected in landfill leachates (Marttinen et al., 2003; Zheng et al., 2007; Ham et al., 2008). Zheng et al. (2007) noted that PAEs were principally bound to the humic acid fraction in leachate, and the distributions of PAEs increased exponentially with increasing molecular weight of the DOM fractions. Particularly, since the heavy metal levels are generally low in landfill leachate (Qu et al., 2008), most estrogenic potentials of leachate, if any, should be basically contributed by the DOM fractions in samples.

This work aims at exploring the correlation between DOM in samples of different landfilling ages and originated from treatment processes and the noted estrogenic potentials. The DOM in leachate from fresh or aged landfills (1-7 years) and in those following

\footnotetext{
* Corresponding author. Tel.: +886 2 23625632; fax: +886 223623040

E-mail address: djlee@ntu.edu.tw (D.-J. Lee).
}

anoxic or aerobic treatments were fractionated using size exclusion chromatography (SEC) technique and characterized using dissolved organic carbon (DOC) contents, $\mathrm{UV}_{254}$ absorbance and fluorescence EEM. Then, the estrogen receptor- $\alpha$ (ER- $\alpha)$ competitor assay was applied to evaluate the estrogenic effects of the collected leachate samples after concentration.

\section{Materials and methods}

\subsection{Leachate samples}

Leachate samples (S1-S5 in Fig. 1) were collected from the Laogang Sanitary Landfill in Shanghai, China. The area-type Laogang Landfill for municipal solid waste was constructed in four phases: Phase I $\left(1.6 \mathrm{~km}^{2}\right)$, II $\left(1.0 \mathrm{~km}^{2}\right)$, III $\left(0.82 \mathrm{~km}^{2}\right)$ and IV $\left(3.3 \mathrm{~km}^{2}\right)$ of the landfill had been operated since 1991, 1996, 2000 and 2005, and had $3000,3000,1500$ and 5000 tons of waste capacity per day, respectively. Leachate sample $S 1$ was sampled from cells accepting waste with average age of 3 months. Sample S2 was from cells from landfill aged 1-2 years. Sample S3 was from cells from landfill aged 3-7 years. The effluent from cells of landfill aged 1-2 years was sent to the anoxic storage pond with a retention time of one month (S4). The overflow from the pond was sent to an aerobic sequential batch reactor (SBR) for polishing before disposal. Sample S5 was leachate collected at SBR outlet.

The leachate samples were filtered through $0.45 \mu \mathrm{m}$ filter made of polypropylene (PP) housing and hydrophilic polytetrafluoroethylene (PTFE) membrane (MFS-25, Pleasanton, Calif., USA). The filtrates were adjusted to $\mathrm{pH} 7$ and stored at $4{ }^{\circ} \mathrm{C}$ no more than one week before analysis. 


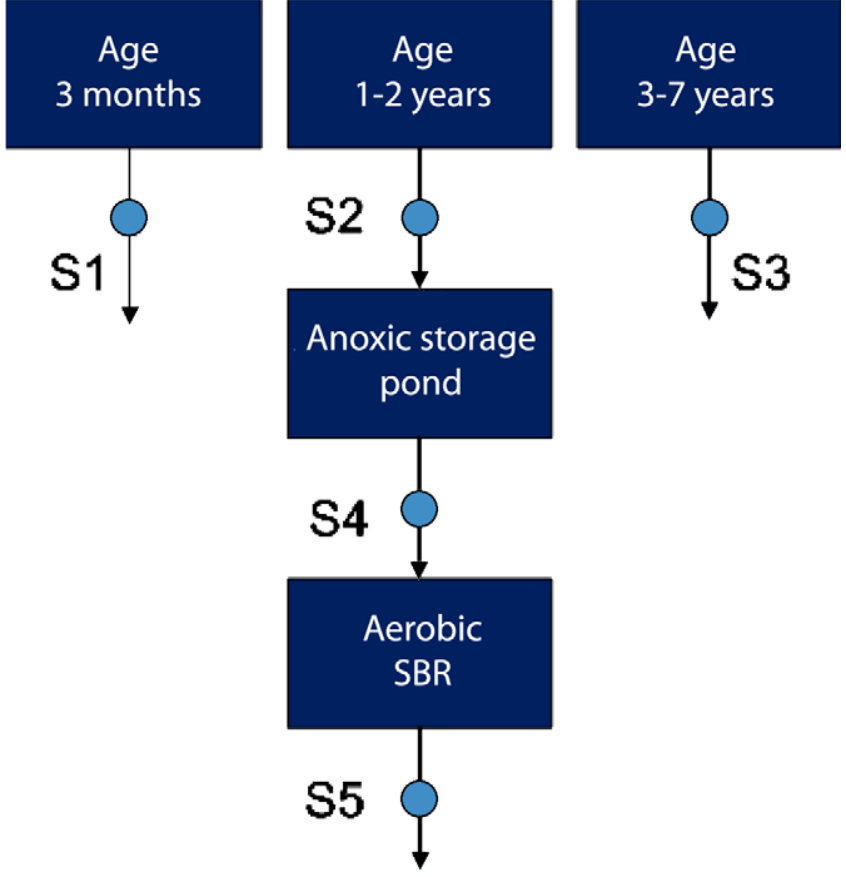

Fig. 1. Sampling points of landfill leachates.

In all tests the potential contamination sources such as unclean cuvette, atmospheric aerosols, impure mobile phase or instrumental noise were minimized for data quality assurance. Milli-Q waters were used as the blank for all tests. All tests were conducted in triplicate with mean and variance reported.

\subsection{Chemical analysis}

The leachate samples were filtered through $0.45 \mu \mathrm{m}$ membrane before analysis. The leachate $\mathrm{pH}$ and oxidation/reduction potential (ORP) were measured using a pH/ORP meter (OAKTON Instruments, IL, USA). Salt concentration was measured by a conductometer (Shanghai Precision \& Scientific Instrument Co., Ltd., Shanghai, China). The carbon and nitrogen content were measured with $\mathrm{TN}_{\mathrm{b}} /$ TC multi N/C 3000 Analyzer (Analytik Jena AG, Jena, Germany). Kjeldahl nitrogen $(\mathrm{KN}), \mathrm{NH}_{4}^{+}-\mathrm{N}, \mathrm{NO}_{3}^{-}-\mathrm{N}$ and total phosphorus (TP) were measured using Standard Methods (APHA, 1998). Organic acids (including lactic acid, volatile fatty acids from $\mathrm{C} 1$ to $\mathrm{C} 6$ as well as iso-C4 and iso-C5) of the $0.20-\mu \mathrm{m}$ filtered samples were measured by high performance liquid chromatograph (HPLC, Shimadzu Co. Ltd., Japan; post-column pH-buffered electroconductivity method). The HPLC was equipped with a LC-20AD solvent delivery unit for mobile phase, a LC-20AD solvent delivery unit for buffer solution, a CDD-10Avp conductive detector, a CTO10ASvp column oven, a SCL-10Avp system controller, a Shim-pack SPR-H analyze column and a LC solution workstation. Table 1 lists the physiochemical characteristics of all samples.

\subsection{Fractionation with SEC}

Size exclusion chromatography was used to fractionate the sample upon its molecular weight distribution. The HPLC-SEC fractionation system was comprised of a BETA 10 Gradient pump (Ecom spol. s r. o., Prague, Czech Republic), a size exclusion HW-50S column (TOYOPEARL resin with 20-40 $\mu$ m particle size, TOSOH Bioscience LLC, Montgomeryville, PA, USA), an on-line SAPPHIRE 600 UV-Vis variable wavelength detector (Ecom spol. s r. o., Prague, Czech Republic), an IOTA 2 refractive index (RI) detector (Precision Instruments, Marseille, France) and a CHF 100SA fraction collector (Advantec MFS, Inc., Dublin, CA, USA). Effluent from the SEC was collected at 3-min intervals and probed by fluorescence EEM and DOC content. A TOC Analyzer (Aurora Model 1030, OI Analytical, College Station, TX, USA) was used to measure the DOC of samples at a detection limit of $0.002 \mathrm{mg}_{-} \mathrm{Cl}^{-1}$.

The flow rate of the pump for SEC testing was $1 \mathrm{ml} \mathrm{min}^{-1}$. The column was operated with a phosphate mobile phase $(0.0024 \mathrm{M}$ $\mathrm{NaH}_{2} \mathrm{PO}_{4}+0.0016 \mathrm{M} \mathrm{Na}_{2} \mathrm{HPO}_{4}, \mathrm{pH} 6.8$ ) containing $0.025 \mathrm{M} \mathrm{Na}_{2} \mathrm{SO}_{4}$ at ionic strength of $0.1 \mathrm{M}$. Polyethylene glycols (PEGs, 200, 1000, 4000,8000 and $20000 \mathrm{~g} \mathrm{~mol}^{-1}$ ) were used for MW calibration of chromatograms. The absorbance wavelength of UV detector was set at $254 \mathrm{~nm}$.

A $2 \mathrm{ml}$ sample was injected into the column. The UV and RI data were collected every $0.05 \mathrm{~s}$. The recovery rates of collected SEC effluents for a 150 min retention period were $97-104 \%$ for S1-S4 and $90 \%$ for $\mathrm{S} 5$, respectively (Table 1 ). Some recovery rates were noted to exceed $100 \%$, which should be attributable to possibly cumulated systematic errors in summing testing DOC values of more than 40 fractions of leachate sample.

\subsection{Fluorescence EEM}

Fluorescence EEM was used to illuminate the nature of DOM (protein-like or humic substance-like) according to the 3D-matrix

Table 1

Physiochemical characteristics of leachate samples

\begin{tabular}{|c|c|c|c|c|c|}
\hline $\begin{array}{l}\text { Sample } \\
\text { Description }\end{array}$ & $\begin{array}{l}\text { S1 } \\
\text { Age } 3 \text { months }\end{array}$ & $\begin{array}{l}\text { S2 } \\
\text { Age } 1-2 \text { years }\end{array}$ & $\begin{array}{l}\text { S3 } \\
\text { Age 3-7 years }\end{array}$ & $\begin{array}{l}\text { S4 } \\
\text { From anoxic storage pond }\end{array}$ & $\begin{array}{l}\text { S5 } \\
\text { SBR effluent }\end{array}$ \\
\hline $\mathrm{pH}^{\mathrm{a}}(-)$ & 5.89 & 7.8 & 8.02 & 7.97 & 8.62 \\
\hline $\mathrm{ORP}^{\mathrm{a}}(\mathrm{mv})$ & -57 & -217 & -75 & -45 & 10 \\
\hline Salt $^{\mathrm{a}}$ (ppt) & 0.7 & 7 & 0.8 & 0.9 & 5.3 \\
\hline $\mathrm{TOC}^{\mathrm{a}}\left(\mathrm{mg} \mathrm{l}^{-1}\right)$ & 22300 & 3480 & 2350 & 2430 & 1290 \\
\hline $\mathrm{IC}^{\mathrm{a}}\left(\mathrm{mg} \mathrm{l}^{-1}\right)$ & 205 & 1790 & 2750 & 2620 & 3430 \\
\hline $\mathrm{TC}^{\mathrm{a}}\left(\mathrm{mg} \mathrm{l}^{-1}\right)$ & 22500 & 5270 & 5100 & 5050 & 4710 \\
\hline $\mathrm{TN}^{\mathrm{a}}\left(\mathrm{mg} \mathrm{l}^{-1}\right)$ & 4110 & 3680 & 4470 & 4320 & 1650 \\
\hline $\mathrm{NH}_{4}^{+}-\mathrm{N}^{\mathrm{a}}\left(\mathrm{mg} \mathrm{l}^{-1}\right)$ & 1900 & 1740 & 2150 & 2060 & 66 \\
\hline $\mathrm{NO}_{3}^{-}-\mathrm{N}^{\mathrm{a}}\left(\mathrm{mg} \mathrm{l}^{-1}\right)$ & 3160 & 136 & 3210 & 2950 & 157 \\
\hline $\mathrm{KN}^{\mathrm{a}}\left(\mathrm{mg} \mathrm{l}^{-1}\right)$ & 2460 & 1980 & 2440 & 2360 & 57 \\
\hline $\mathrm{TP}^{\mathrm{a}}\left(\mathrm{mg} \mathrm{l}^{-1}\right)$ & 31.2 & 13.6 & 13.3 & 12.4 & 7.74 \\
\hline $\mathrm{DOC}^{\mathrm{b}}\left(\mathrm{mg} \mathrm{l}^{-1}\right)$ & 19900 & 3490 & 848 & 1400 & 458 \\
\hline DOC/TOC (-) & 0.89 & 1.00 & 0.36 & 0.58 & 0.36 \\
\hline Recovery $^{c}(\%)$ & 97 & 100 & 104 & 102 & 90 \\
\hline
\end{tabular}

\footnotetext{
a The values for whole leachate samples without filtration

b The DOC values are TOC for samples following $0.45-\mu \mathrm{m}$ filtration.

c The DOC recovery rate of SEC effluent collection for $150 \mathrm{~min}$ to the inject sample.
} 
fluorescent fingerprints. The fluorescence EEM spectra of leachate samples were measured by a Cary Eclipse fluorescence spectrophotometer (Varian Inc., Palo Alto, CA, USA). The EEM spectra were collected with scanning emission wavelength of 250-600 nm at $2 \mathrm{~nm}$ increments and excitation wavelength of $200-500 \mathrm{~nm}$ at $10 \mathrm{~nm}$ increments. The spectra were recorded at a scanning rate of $1200 \mathrm{~nm} \mathrm{~min}{ }^{-1}$ using excitation and emission slit bandwidths of $5 \mathrm{~nm}$. Before each scan, the cuvettes were rinsed and ultrasonicated with $5 \%(\mathrm{w} / \mathrm{w})$ nitric acid solution. The washed liquor of the cuvettes, the Milli-Q water and the effluent of mobile phase from SEC were scanned before each fluorescence analysis to ensure the absence of contaminants.

As suggested in a previous study by Baker (2001), EEM analyses were performed at $25 \pm 2{ }^{\circ} \mathrm{C}$, and blank scans were run every 5-15 analyses using Milli-Q water. The Raman peak of water at an excitation of $348 \mathrm{~nm}$ was used to test machine stability. Raman emission at $395 \mathrm{~nm}$ averaged $17.2 \pm 0.8 \mathrm{~nm}(n=50)$, and no drift was noted throughout the testing period. All data were collected using the same instrument for quality assurance. Hence, absorbance correction for tryptophan fluorescence was unnecessary (Ohno, 2002; Baker and Curry, 2006). The intensities yielded from Rayleigh and Raman scatters were subtracted from the collected scanned data. The Bahram et al. (2007) protocol was applied when analyzing the first- and second-order Rayleigh and Raman scatters to reduce interference.

\subsection{Estrogen receptor- $\alpha$ competitor assay}

The leachate samples and SEC fractions were concentrated by solid phase extraction (SPE) for the estrogen receptor- $\alpha$ competitor assay (ERCA).

SPE was performed using OASIS HLB cartridges $\left(6 \mathrm{~cm}^{3}, 500 \mathrm{mg}\right.$ OASIS HLB, Waters Corporation, USA). The HLB tubes were conditioned with $5 \mathrm{ml}$ methanol (Supelco, for pesticide residue analysis) and $5 \mathrm{ml}$ Milli-Q water in sequence. Then $10 \mathrm{ml}(\mathrm{S} 2-\mathrm{S} 4)$ or $20 \mathrm{ml}$ (S1 and S5) of the samples were flowed through the tubes, followed by cartridge washing with $5 \mathrm{ml}$ of Milli-Q water. After drying with nitrogen gas for about $30 \mathrm{~min}$, the cartridges were rinsed twice with $5 \mathrm{ml}$ of methanol. The eluted solutions were evaporated under nitrogen gas to dryness. The residues were then dissolved in $0.2 \mathrm{ml}$ of DMSO (concentrated by 50 times for S2-S4 and 100 times for S1 and S5). Series of six dilutions (1, 1/5, 1/25, 1/100,1/500, 1/ 2500 ) for the SPE concentrated samples were prepared in DMSO for bioassay analysis.

Estrogen receptor- $\alpha$ (ER- $\alpha$ ) Competitor Screening Kit (Wako Pure Chemical Industries, Ltd., Japan) was used to estimate the estrogenic potential of the leachate samples. The assay was applied to identify and monitor environmental pollutants (Suzuki et al., 2004). The assay was performed according to the manufacturer's protocol. In brief, $5 \mu \mathrm{l}$ of the sample and $95 \mu \mathrm{l}$ of the reaction solution were reacted for $2 \mathrm{~h}$ at room temperature (about $20^{\circ} \mathrm{C}$ ) in the microplate well coated with ER- $\alpha$. Then the mixture was discarded and the wells were rinsed by $200 \mu \mathrm{l}$ of wash solution twice. Hundred microliters of assay solution was added to dissolve the coated ER- $\alpha$, and analyzed in a Multi-Detection Microplate Reader (Synergy HT, BioTek, USA) at Ex 485 nm, Em 535 nm. Two wells without coating were used as the blank. For each dilution, two replicates were tested. Each leachate sample was tested for 6 dilutions. All samples were measured in the same test. $17 \beta$-estradiol were assessed simultaneously as positive control. The inhibition ratio was calculated as
Classical dose-response curve was applied to correlate inhibition data, using the 4-parameter sigmoidal equation as

$$
y=\min +(\max -\min ) /\left(1+\left(x / \mathrm{IC}_{50}\right)^{\text {hill slope }}\right)
$$

\section{Results}

\subsection{SEC profile}

As listed in Table 1, the fresh leachate S1 had DOC of $19900 \mathrm{mg} \mathrm{l}^{-1}$. After $1-2$ years or 3-7 years in landfill, the corresponding DOC of S2 and S3 had been reduced respectively to 3490 and $848 \mathrm{mg} \mathrm{l}^{-1}$, indicating $82.5 \%$ and $95.7 \%$ removal. The anoxic storage of S2 reduced the DOC from 3490 to $1400 \mathrm{mg} \mathrm{l}^{-1}$ (S4). Final aerobic SBR treatment further reduced the DOC to $458 \mathrm{mg} \mathrm{l}^{-1}$ (S5).

Over 95\% of DOC in 300-1800 Da in S1 was not found in S2. Hence, for the sake of further discussion, the MW distributions of DOM in the samples $\mathrm{S} 1$ can be categorized into three groups based on DOC contents (Fig. 2a): MW $>1800$ Da (retention time $<60$ $\mathrm{min})$, 300-1800 Da (60-80 min) and <300 Da (>80 min), which comprised $3.8 \%$ (756 $\mathrm{mg} \mathrm{l}^{-1}$ ), 85.2\% (17000 $\mathrm{mg} \mathrm{l}^{-1}$ ) and $14.0 \%$ $\left(2190 \mathrm{mg} \mathrm{l}^{-1}\right)$, respectively, of DOC in S1. The S2 of landfill aged 1-2 years mainly consisted of small organic molecules $(41.5 \%$ $<300 \mathrm{Da}$ ) (Fig. 2b). In S3, the DOC fractions of MW > $1800 \mathrm{Da}$, 300-1800 Da and <300 Da were 50.2\% (425 $\left.\mathrm{mg} \mathrm{l}^{-1}\right), \quad 20.1 \%$ (252 $\mathrm{mg} \mathrm{l}^{-1}$ ) and $29.7 \%\left(170 \mathrm{mg} \mathrm{l}^{-1}\right.$ ), respectively (Fig. 2c). Hence, most DOM of MW $<1800$ Da were degraded in landfill aged 3-7 years.

The anoxic pond and aerobic SBR significantly reduced DOC in S2 of MW <1800 Da (S4 in Fig. 2d and S5 in Fig. 2e).

Fig. 3 presents the UV absorbance profile of DOM when it was excluded gradually out of SEC resins. When the molecular weight of DOM fell in the range of 200-20000 Da, the molecular weight was quantitatively corresponded to SEC retention time. The leachate from fresh waste (S1) had low $\mathrm{UV}_{254}$ (normalized by total DOC of the sample) (Fig. 3). Most of the $\mathrm{UV}_{254}$-absorbing substances in S1 had MW of $1.5-3.0 \times 10^{4} \mathrm{Da}$. The S2 (1-2 years landfill age) and S3 (3-7 years landfill age) had a peak MW of 200-300 Da and some peaks at MW of $2 \times 10^{3}-2 \times 10^{4} \mathrm{Da}$. The S2 had significant levels of $\mathrm{UV}_{254}$-absorbing substances of MW 1.5-5 $\times 10^{4}$ Da. Overall $\mathrm{UV}_{254}$ absorbance was lower in S2 than in S3. Restated, aromaticity per unit DOC of residual compounds increased with landfill age.

The UV absorbance in S2 over MW $1.5 \times 10^{4}-5 \times 10^{4}$ decreased significantly following anoxic storage (S4). The SBR treatment eliminated the UV absorbance of MW $1.5 \times 10^{4}-3 \times 10^{4} \mathrm{Da}$ and that of 200-300 Da, but, contrastingly, increased the UV absorbance over MW range of 4000-20000 Da (S5).

Fig. E1 in Electronic Supplementary material shows the fluorescent EEM spectra of bulk leachate samples. The locations of characteristic peaks included (Ex/Em in $\mathrm{nm} \mathrm{nm}^{-1}$ ) 220/300, 220/350, $270 / 300,280 / 360,240 / 450,310 / 420,310 / 450$ and 420/470, with the former four and the latter four corresponding to the biological by-products of aromatic proteins and humic substances, respectively.

The leachate S1 had biological by-products, protein-like substances and few humic substances (Fig. E1a). As landfill age increased, intensity of humic-peaks increased and that of protein-peaks decreased (Fig. E1a, E1b and E1c). Anoxic pond had no significant effect on the protein/humic fractions in S4 compared

Inhibition ratio $(\%)=100-\frac{(\text { fluorescent intensity of the sample })-(\text { fluorescent intensity of the blank })}{(\text { fluorescent intensity of pure DMSO })-(\text { fluorescent intensity of the blank })} \times 100 \%$ 
(a)

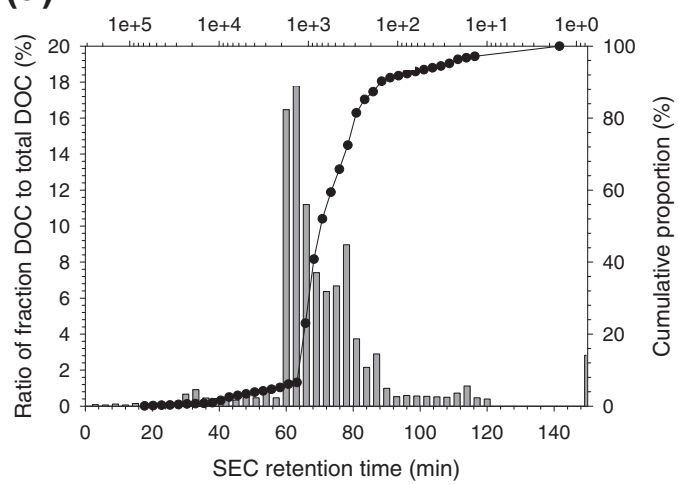

(c)

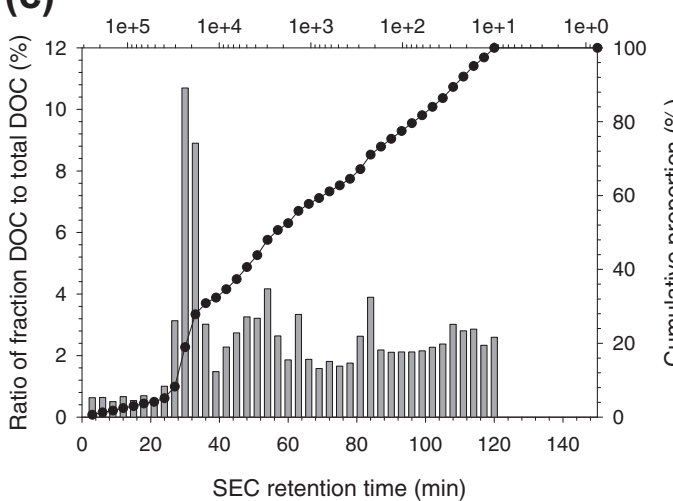

(b)

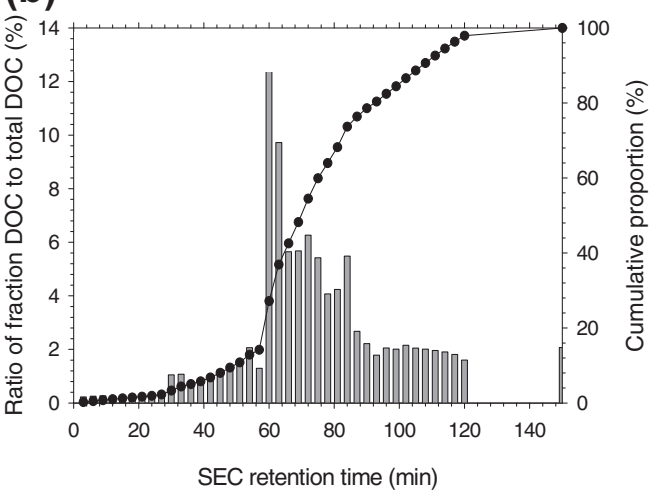

(d)

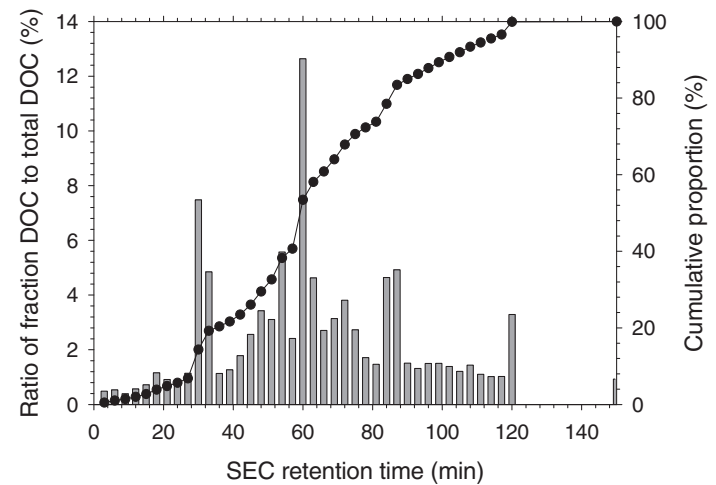

(e)

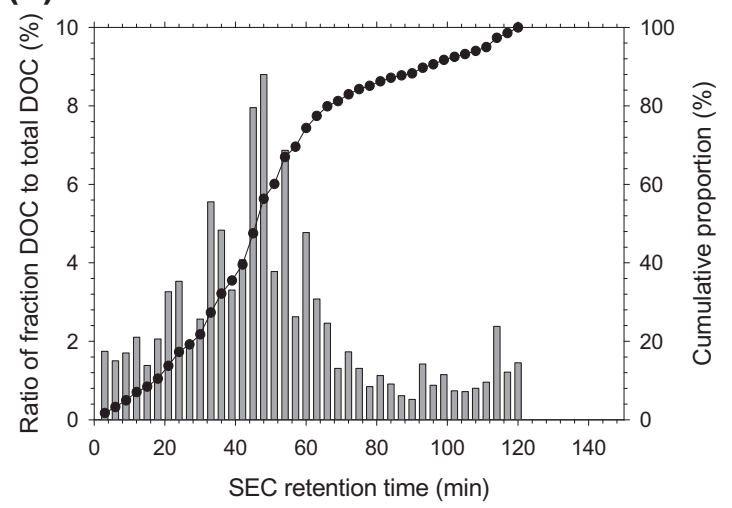

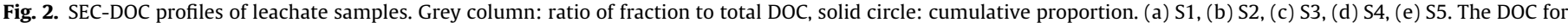
S1-S5 were $19900,848,3490,1400$, and $458 \mathrm{mg} \mathrm{l}^{-1}$, respectively.

with S3 (Fig. E1d). Aerobic SBR treatment removed most proteinpeaks and significantly enhanced the humic-peaks (Fig. E1e).

The fractional tests elucidated the chemical natures of DOM in a specific MW range. The S2 of landfill aged 1-2 years had $23.9 \%$ of

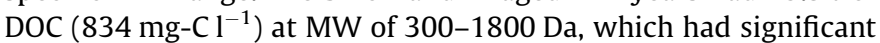
fluorescent emission (Fig. E1) but no $\mathrm{UV}_{254}$ absorbance (Fig. 3). Over 95\% compounds in this MW range in S1 was degraded within 1-2 years in landfill. The DOC with MW of 1800-10000 Da or $<300 \mathrm{Da}$ were 349 and $1450 \mathrm{mg}-\mathrm{Cl}^{-1}$, approximately $46 \%$ and $66 \%$, respectively of the corresponding content in S1.

Over 3-7 years in landfill, the S3 had $20.1 \%$ of DOC $(170 \mathrm{mg}$ $\mathrm{Cl}^{-1}$ ) with MW of 300-1800 Da. Restated, over 99\% DOM in this MW range in S1 was completely degraded in landfill. After seven years of landfill, the DOM in leachate at MW < 300 Da was further degraded by $54 \%$ while that at MW > 1800 Da exhibited no further degradation in the landfill.

\subsection{Estrogenic potential of leachate}

After SPE concentration, most of the leachate samples exhibited an inhibition ratio $>50 \%$ (Fig. 4). According to the classical dose-response curve, the $\mathrm{IC}_{50}$ values were estimated to be $7.0,9.9,6.1$, and 4.5 concentration folds for S1-S4, respectively. Although lacking sufficient data span, the $\mathrm{IC}_{50}$ value for $\mathrm{S} 5$ should be $>100$ concentration fold. In this assay, $\mathrm{IC}_{50}$ corresponded to a estrodiol equivalent of $7 \mathrm{nmol}^{-1}$, when taking $17 \beta$-estradiol as standard. Correspondingly, the $\mathrm{IC}_{20}$ values were estimated to be $2.3,0.7$, $0.68,0.53$ and 5.7 concentration folds for S1-S5, respectively.

It should be mentioned that since the compositions of deposited waste and collection strategy changed over time, the difference in $\mathrm{IC}_{50}$ values noted for S1-S3 cannot be justified significant. Conversely, the changes in estrogenic potential following anoxic/aerobic treatments by comparing S2, S4, and S5 are relevant because 


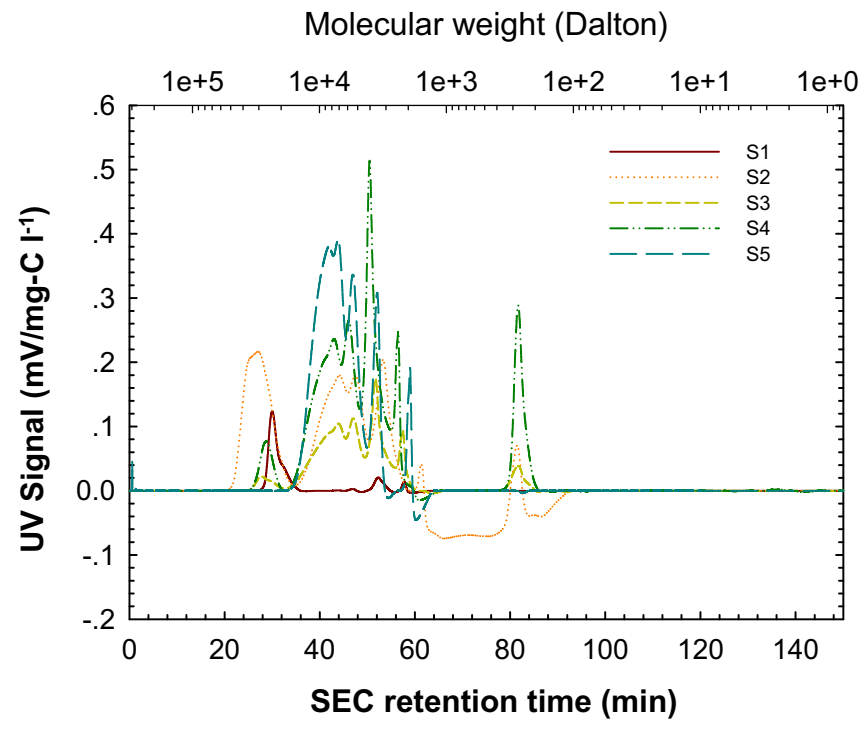

Fig. 3. SEC-UV chromatogram normalized by total DOC.

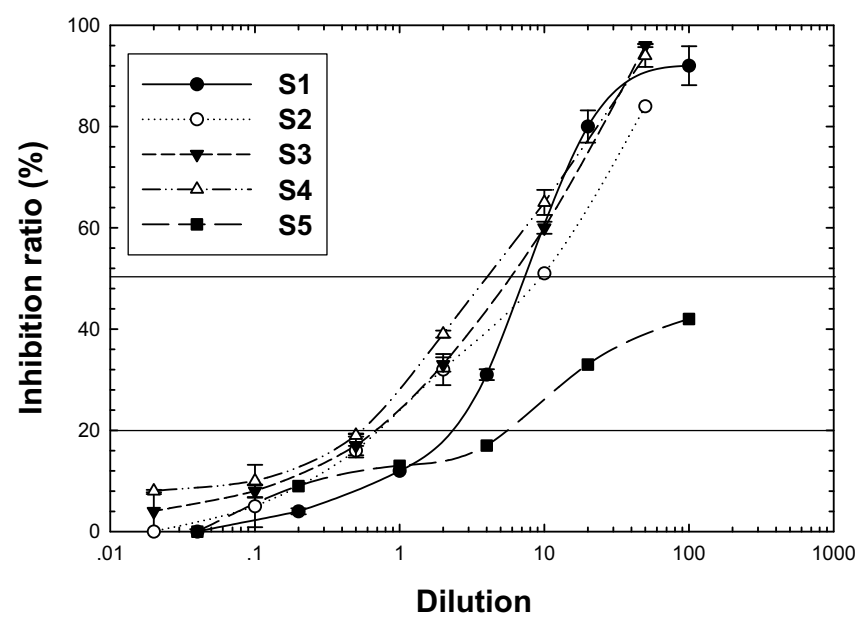

Fig. 4. Estrogenic inhibition ratios of the concentrated leachate samples.

the samples were directly derived from each other. The $\mathrm{IC}_{50}$ and $\mathrm{IC}_{20}$ values hence follow S5 $\gg \mathrm{S} 1-\mathrm{S} 4$. Although landfilling significantly reduced leachate COD and levels of other pollutants (Table 1 ), aging or anoxic storage in pond had little impact on estrogenic potential of leachate. Aerobic SBR treatment significantly reduced the estrogenic potential of leachate $\mathrm{S} 5$. According to $\mathrm{IC}_{50}$, the depuration rate of estrogenic potential for S1 $\rightarrow$ S2 was 30\%, while the DOC decreased by $83 \%$. This may suggest that the degraded DOM during 1-2 landfilling was the part that has low estrogenic potentials. The depuration rate of estrogenic potential for S2 $\rightarrow$ S5 was more than $90 \%$, while the DOC decreased by $87 \%$, indicating that aerobic SBR eliminated the fraction of DOM with high estrogenic potentials.

The SEC effluents were divided into part 1-4 based on MW ranges: >14000 Da, 3000-14000 Da, 600-3000 Da, and <600 Da for estrogenic potential tests. Fig. 5 shows the inhibition ratios of the leachate parts for S2-S5 at dilution of one. For leachate samples with different landfill ages (comparing S2 and S3) and treatment processes (comparing S2, S4, and S5), part 2 always revealed the highest inhibition ratios, followed by part 4,3 , and 1 . The assays at other dilutions $(0.25,0.05,0.01$ and 0.002$)$ also revealed the consistent results. Restated, the estrogen potential of the leachate was mainly contributed by organic matters of moderate MW (3000-

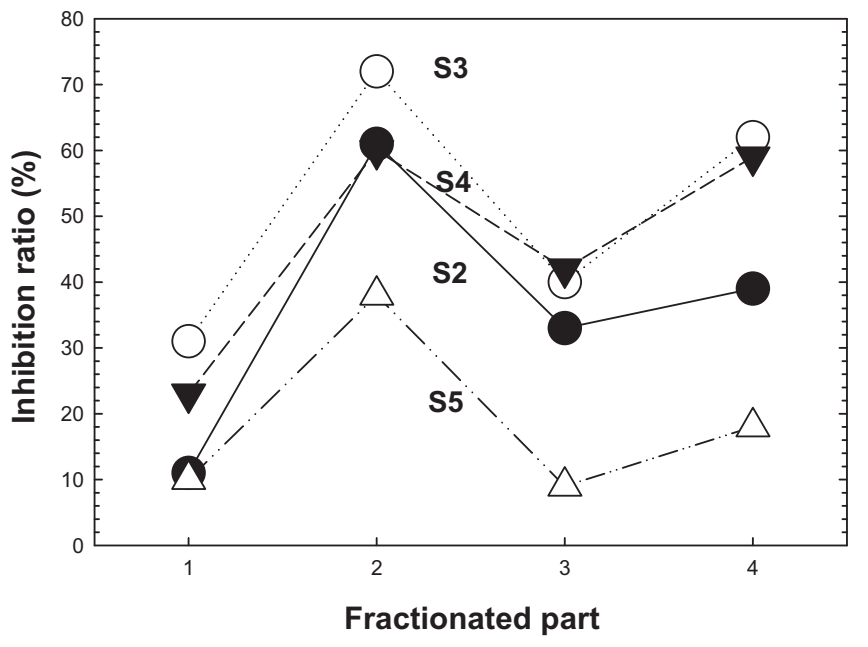

Fig. 5. Estrogenic inhibition ratios of the fractionated leachate samples. Part 1: $>14000 \mathrm{Da}$; part 2: 3000-14000 Da; part 3: 600-3000 Da, part 4: <600 Da.

$14000 \mathrm{Da})$, followed by those of low MW (<600 Da). As Fig. 5 reveals, the landfill aging could slightly increase estrogenic inhibition ratio for parts $2-4(<14000 \mathrm{Da})$, while anoxic storage at pond could slightly decrease inhibition ratios of part 2 . On the other hand, aerobic SBR treatment considerably reduced inhibition ratios of part $2-4$.

\section{Discussion}

The leachate following anoxic storage (S4) had $28.1 \%$ of DOC (392 $\mathrm{mg}_{-} \mathrm{Cl}^{-1}$ ) at MW of $300-1800 \mathrm{Da}$. Over $88 \%$ compounds in this MW range in S2 had been degraded under anoxic conditions (S4). In S5, under aerobic conditions, the SBR degraded 84\% DOM in the same MW range from S4. However, neither anoxic storage nor aerobic SBR degraded DOM in MW > 1800 Da in terms of DOC.

The EEM spectra of leachate (comparing Fig. E1c-e) did not vary with landfill age (Baker and Curry, 2006). Peak overlapping and multi-fluorophores of probed substances may be problematic when extracting optimal components in parallel factor analysis (Hua et al., 2007) or adopting the scan area partition method (Chen et al., 2003) from EEM spectra. The volumetric fluorescence intensity, defined as the integration of the volume under fluorescence EEM surface and normalized by the scan area (excitation of 200$500 \mathrm{~nm}$ and emission of 250-600 nm) was normalized by fractional DOC (Fig. E2 in Electronic Supplementary material). The fluorescent compounds were noted at seven MW ranges (Da): 23000-24000, $8000-9000,5000,3000,1800,1000-1100$ and 200-250. The fractional characteristics of SEC fractions were listed in Fig. E3 in Electronic Supplementary material for comparison sake.

The change in estrogenic potential for S2-S4 correlates with the noted increase in aromatic organic compound contents with high $\mathrm{UV}_{254}$ and with intermediate (2000-20000 Da) or low MW (200$300 \mathrm{Da}$ ) (Fig. 3). Aerobic SBR treatment yielded leachate of low $\mathrm{UV}_{254}$ (Fig. 3), correlating with the noted decrease in estrogenic potential (Figs. 4 and 5). The current landfill practice degrades most organic matters in waste, but cannot effectively remove estrogens from the leachate. Subsequent stage such as the aerobic SBR treatment adopted here can polish the leachate for reducing its estrogen threat to receiving body, like groundwater.

\section{Conclusions}

The DOM in leachate samples collected at Laogang Sanitary Landfill in Shanghai, China were fractionated by MW using SEC 
with DOC, $\mathrm{UV}_{254}$, and EEM as classification indices. The landfilling or storage in anoxic pond could not significantly affect the estrogenic potential of leachate. The $\mathrm{IC}_{50}$ values of $\mathrm{S} 1-\mathrm{S} 5$ are estimated $7.0,9.9,6.1,4.5$, and $>100$ concentration folds, respectively. Restated, although landfilling or anoxic storage effectively degraded pollutant levels in leachate, the residual organic matters of high aromaticity present strong estrogenic potential. Particularly, the residues of MW 3000-14000 Da and of $<600 \mathrm{Da}$ contributed most of the estrogenic activities in leachate. Conversely, aerobic SBR treatment considerably reduced the estrogenic potential of these organic matters in leachate.

\section{Acknowledgements}

F.L. thanks YZU for appointing her as a postdoc fellow since 2007, February. The Key Programs of the National Natural Science Foundation of China (NSFC) (50538080), National Science Council and Ministry of Education of Taiwan, National Hi-Tech Research and Development Program of China (2003AA644020) partially supported this research.

\section{Appendix A. Supplementary material}

Supplementary data associated with this article can be found, in the online version, at doi:10.1016/j.chemosphere.2008.04.015.

\section{References}

APHA, AWWA, WEF, 1998. Standard Methods for the Examining of Waste and Wastewater, 20th ed. American Public Health Association, Washington, DC.

Bahram, M., Bro, R., Stedmon, C., Afkhami, A., 2007. Handling of Rayleigh and Raman scatter for PARAFAC modeling of fluorescence data using interpolation. J. Chemometr. 20, 99-105.

Baker, A., 2001. Fluorescence excitation-emission matrix characterization of some sewage-impacted rivers. Environ. Sci. Technol. 35, 948-953.

Baker, A., 2005. Fluorescence tracing of diffuse landfill leachate contamination in rivers. Water Air Soil Pollut. 163, 229-244

Baker, A., Curry, M., 2006. Fluorescence of leachates from three contrasting landfills. Water Res. 38, 2605-2613.
Chen, W., Westerhoff, P., Leenheer, J.A., Booksh, K., 2003. Fluorescence excitationemission matrix regional integration to quantify spectra for dissolved organic matter. Environ. Sci. Technol. 37, 5701-5710.

Christensen, J.B., Jensen, D.L., Gron, C., Filip, Z., Christensen, T.H., 1998 Characterization of the dissolved organic carbon in landfill leachate-polluted groundwater. Water Res. 32, 125-135.

Frimmel, F.H., Weis, M., 1991. Aging effects of high-molecular-weight organic-acids which can be isolated from landfill leachates. Water Sci. Technol. 23, 419-426.

Gobbels, F.-J., Puttmann, W., 1997. Structural investigation of isolated aquatic fulvic and humic acids in seepage water of waste deposits by pyrolysis-gas chromatography/mass spectrometry. Water Res. 31, 1609-1618.

Ham, S.Y., Kim, Y.J., Lee, D.H., 2008. Leaching characteristics of PCDDs/DFs and dioxin-like PCBs from landfills containing municipal solid waste and incineration residues. Chemosphere 70, 1685-1693.

He, P.J., Xue, J.F., Shao, L.M., Li, G.J., Lee, D.J., 2006. Dissolved organic matter (DOM) in recycled leachate of bioreactor landfill. Water Res. 40, 1465-1473.

Hua, B., Dolan, F., McGhee, C., Clevenger, T.E., Deng, B.L., 2007. Water-source characterization and classification with fluorescence EEM spectroscopy: PARAFAC analysis. Int. J. Environ. Anal. Chem. 87, 135-147.

Kjeldsen, P., Barlaz, M.A., Rooker, A.P., Baun, A., Ledin, A., Christensen, T.H., 2002 Present and long-term composition of MSW landfill leachate: a review. Crit Rev. Environ. Sci. Technol. 32, 297-336.

Klein, T., Niessner, R., 1998. Characterization of heavy-metal-containing seepage water colloids by flow FFF, ultrafiltration, ELISA and AAS. Mikrochim. Acta 129 47-55.

Marttinen, S.K. Kettunen, R.H. Rintala, J.A 2003. Occurrence and removal of organic pollutants in sewages and landfill leachates. Sci. Total Environ. 301, 112.

Ohno, T., 2002. Fluorescence inner-filtering correction for determining the humification index of dissolved organic matter. Environ. Sci. Technol. 36, 742-746.

Persson, L., Alsberg, T., Ledin, A., Odham, G., 2006. Transformations of dissolved organic matter in a landfill leachate - a size exclusion chromatography/mass spectrometric approach. Chemosphere 64, 1093-1099.

Qu, X., He, P.J., Shao, L.M., Lee, D.J., 2008. Heavy metals mobility in full-scale bioreactor landfill: initial stage. Chemosphere 70, 769-777.

Saadi, I., Borisover, M., Armon, R., Laor, Y., 2006. Monitoring of effluent DOM biodegradation using fluorescence, UV and DOC measurements. Chemosphere $63,530-539$.

Suzuki, T., Nakagawa, Y., Takano, I. Yaguchi, K., Yasuda, K., 2004. Environmental fate of bisphenol A and its biological metabolites in river water and their xenoestrogenic activity. Environ. Sci. Technol. 38, 2389-2396.

Weis, M., Abbt-Braun, G., Frimmel, F.H., 1989. Humic-like substances from landfill leachates - characterization and comparison with terrestrial and aquatic humic substances. Sci. Total Environ., 343-352.

Zheng, Z., He, P.J., Shao, L.M., Lee, D.J., 2007. Phthalic acid esters in dissolved fractions of landfill leachates. Water Res. 41, 4696-4702. 